\title{
Depression as a Mental Health Problem in the Patients Suffering from Cancer
}

\author{
Behzad Saberi* \\ Medical Research, Esfahan, Iran
}

*Corresponding author: Behzad Saberi, Medical Research, Esfahan, Iran.

\section{Short Communication}

About two patients from every ten patients who have been diagnosed with cancer, suffer from depression. This depression is something apart from usual sadness. Patients who have been diagnosed with cancer may encounter various stressful issues. Depression in this patients group can be occurred and needs special attention to be diagnosed and be treated appropriately. Issues like changes in daily life and life plans, changes in self-confidence and body image, being afraid of death and being worried about legal and money issues are some examples about such stressful issues for the cancer patients. When a patient is diagnosed with cancer, he or she would encounter with various degrees of grief and sadness and some other symptoms related to the depression like having problem with sleep and appetite, being worried about the future and related anxiety and some feelings like despair, disbelief and also denial. Although these are common symptoms in the patients who have been diagnosed with cancer, but the reaction of the patients and their degrees of possible depression is different between various patients. Some patients can deal with the diagnosis of cancer better and would not encounter depression and anxiety problems and some others deal with such diagnosis in a way that they would encounter anxiety disorder and major depressive disorder. Usually the patients who can continue their roles in their lives like being a parent or a spouse and can be active during their daily life, have adjusted to the cancer diagnosis and its course much better than other patients. Family members of the patients who have been diagnosed with cancer, are also at risk of developing anxiety and depression.

There are some factors which can increase the risk of the patients with cancer to develop depression. Factors like taking some medications including alfa Interferon, Corticosteroids, Amphotericin B, Procarbazine, Interleukin-2 and L-asparaginase, having some degrees of depression while being diagnosed with cancer, being diagnosed with advanced cancer and poor prognosis, being diagnosed with pancreatic cancer, encountering weakness and pain and having some specific feelings like being a problem for or a burden to other people, are the major ones which can increase the risk of developing depression in the patients with cancer. Having a family or personal history of suicide, depression, alcohol and drug use and mental problems, having a stressful life, lack of having family or close friends supports and having concomitant diseases which they can cause depression themselves like heart diseases and stroke, having thyroid and adrenal hormones imbalances, having anemia or fever, abnormalities in the blood levels of sodium, calcium and potassium and having deficiencies in Folate or B12 vitamin, would also increase the risk of developing depression in the patients who have been diagnosed with cancer. Depression as a mental health problem is an important issue in the patients with cancer and should be diagnosed and be treated appropriately. Having knowledge about the factors which would increase the risk of developing depression in the patients who are suffering from various types of cancer and also having knowledge about the proper diagnostic and treatment methods for such depression as a mental health problem in this patients group, are necessary for the physicians and health care professionals who are dealing with the cancer patients during clinical practice [1-9].

\section{Acknowledgement}

None.

\section{Conflict of Interest}

No conflict of interest.

\section{References}

1. Jack L, Scott A, Colvin L, Laird B, Fallon M (2011) Pain and depression in cancer patients: a longitudinal study. BMJ Support Palliat Care. 
2. Gao LP, Weng CS (2008) Influencing factors of quality of life in cancer patients of initial stages receiving radio- and chemotherapy and its countermeasures. Nurs J Chin People's Liberation Army 8: 10-12.

3. Spijker AV, Trijsberg RW, Duivenvoorden HJ (1997) Psychological sequelae of cancer diagnosis: a meta-analytical review of 58 studies after 1980. Psychosom Med 59(3): 280-293.

4. Chapman CR (1979) Psychological and behavioral aspects of cancer pain. Adv Pain Res Ther 2: 45-56.

5. Liu Y, Wang YF, Shong LQ (2007) The progress in the study on depression of cancer patients. Chin J of Beh Med Sci l16(11): 1054-1056.
6. Strong V, Waters R, Hibberd C, Rush R, Cargill A, et al. (2007) Emotional distress in cancer patients: the Edinburgh Cancer Centre symptom study. Br J Cancer 96(6): 868-874.

7. Massie MJ (2004) Prevalence of depression in patients with cancer. J Natl Cancer Inst Monogr 32: 57-71.

8. Chen ML, Zhang HK, Yeh CH (2000) Anxiety and depression in Taiwanese cancer patients with and without pain. J Adv Nurs 32(4): 944-951.

9. Evans DL, McCartney CF, Nemeroff CB, Raft D, Quade D, et al. (1986) Depression in women treated for gynecological cancer: clinical and neuroendocrine assessment. Am J Psychiatry 143(4): 447-451. 